\title{
Subungual osteochondroma: case report and review of clinical, radiologic and ultrasound presentation versus subungual exostosis
}

\begin{abstract}
While osteochondromas represent the most common primary bone tumors of the foot, the subungual presentation is less frequent. These lesions appear as firm solitary nodules with a tendency to grow, causing deformity of the overlying nail. We present the case of subungual osteochondroma with its characteristic clinical and radiologic features, adding the complementary visualization of its ultrasound findings, which have barely been described in published literature, unlike the subungual exostosis, its main differential diagnosis.
\end{abstract}

Keywords: ultrasonography, subungual osteochondroma, nail disorders, neoplasmsbenign
Volume 4 Issue 4 - 2020

\author{
Laura Vergara-de-la-Campa,' Álvaro \\ González-Cantero, ${ }^{2}$ Obdulia Garcia- \\ Olmedo,' J González Cantero ${ }^{3}$ \\ 'Department of Dermatology, Complejo Hospitalario de Toledo, \\ Spain \\ 2Department of Dermatology, Hospital Universitario Ramón y \\ Cajal, Spain \\ 3Department of Radiology, Hospital Carlos Haya de Málaga, \\ Spain
}

Correspondence: Laura Vergara de la Campa, Department of Dermatology, Complejo Hospitalario de Toledo, Spain, Tel +34 638186844 Email laura.vergara.de.la.campa@gmail.com

Received: August 15, 2020 | Published: August 28, 2020

\section{Abbreviations: US; ultrasound \\ Introduction}

Osteochondromas represent the most common bone tumor. They are benign osteocartilaginous outgrowths that affect bones with endochondral growth affecting in very few cases small bones, when these tumors settle under the skin they are termed subungual osteochondromas. ${ }^{2-4}$ They are, altogether with subungual exostosis, the most common bony lesions affecting the nail unit. ${ }^{5}$ Some authors consider subungual exostosis a variant of osteochondroma or even a single entity ${ }^{1,5,6}$ whereas others have described differences among them ${ }^{7,8}$ one of these being its US findings (Table 1).

Table I Differential diagnosis between subungual osteochondroma and subungual exostosis

\begin{tabular}{|c|c|c|}
\hline & Subungual osteochondroma & Subungual exostosis \\
\hline Bone origin & Endochondral ossification $1,5,17$ & Fibrous tissue $e^{1,5,17}$ \\
\hline $\begin{array}{l}\text { Location of the bony } \\
\text { excrescence }\end{array}$ & In proximity with the metaphyseal area ${ }^{2,8,9}$ & Distal, not related to the metaphyseal area $2,8,9$ \\
\hline Histology & Cap is composed of hyaline cartilage $2,8,9$ & Cap is composed of fibrocartilage $2,8,9$ \\
\hline Radiography findings & $\begin{array}{l}\text { Juxtaepiphyseal protuberances in continuity with } \\
\text { the underlying bone cortex and medullary channel } \\
1,2,9\end{array}$ & $\begin{array}{l}\text { Protuberances lack clear continuity of both the } \\
\text { medullary cavity and cortex } 1,4,9,10\end{array}$ \\
\hline Ultrasound findings & $\begin{array}{l}\text { Well-defined rounded hypoechoic images with } \\
\text { increased vascularization }\end{array}$ & $\begin{array}{l}\text { Hyperechoic linear images, with posterior acoustic } \\
\text { shadowing with relative hypovascularity or mild } \\
\text { vascularity }\end{array}$ \\
\hline
\end{tabular}

\section{Case synopsis}

A 12-year-old male, with no relevant medical history, was evaluated for a painful outgrowth under the second toenail of his left foot for over a month and a half, coinciding with the beginning of soccer season. Physical examination revealed a yellowish hyperkeratotic subungual tumor with a well-defined erythematous base protruding towards the medial side of the nail plate. Dermoscopy showed a yellowishbrown hyperkeratotic protuberance over an erythematous nodule with linear vessels, and no atypia signs (Figure 1). Short and long axis images of high-resolution ultrasound (US) of the medial aspect of the distal phalanx showed a hypoechoic band in keeping with the cartilaginous cap, bounded by an echogenic bony protuberance on its deep surface, enlarging the nail bed and displacing upwards the nail plates (Figure 2). X-ray of the foot showed a bony excrescence in the distal phalanx, compatible with an osteochondroma (Figure 3). The patient was referred to the department of Traumatology for surgical removal and diagnosis confirmed by histopathological examination. 


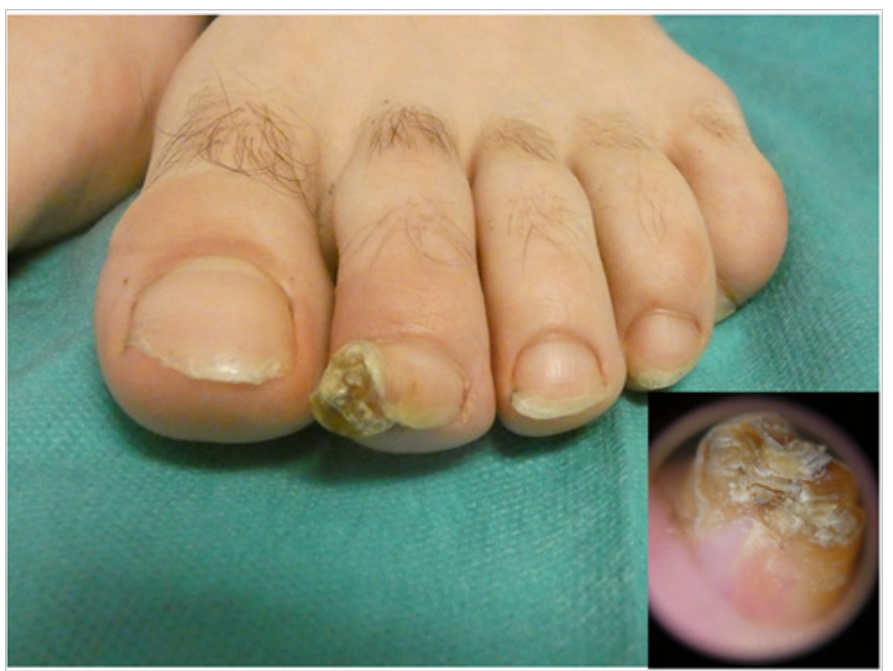

Figure I Yellowish hyperkeratotic subungual tumor with erythematous nodule protruding towards the medial side of the nail plate. On the left, dermoscopy revealed a yellowish-brown hyperkeratotic protuberance over a pink-erythematous base without atypia signs.
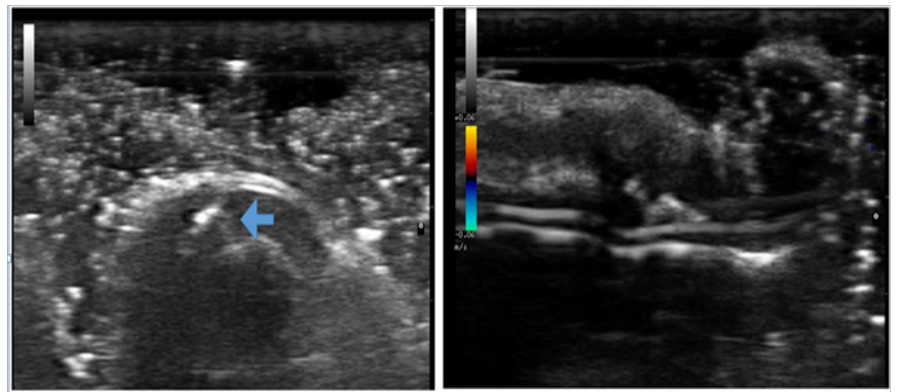

Figure 2 Short (left) and long (right) axis US images showed a hypoechoic band in keeping with the cartilaginous cap, bounded by an echogenic bony protuberance(arrow) on its deep surface, enlarging the nail bed and displacing upwards the nail plates.
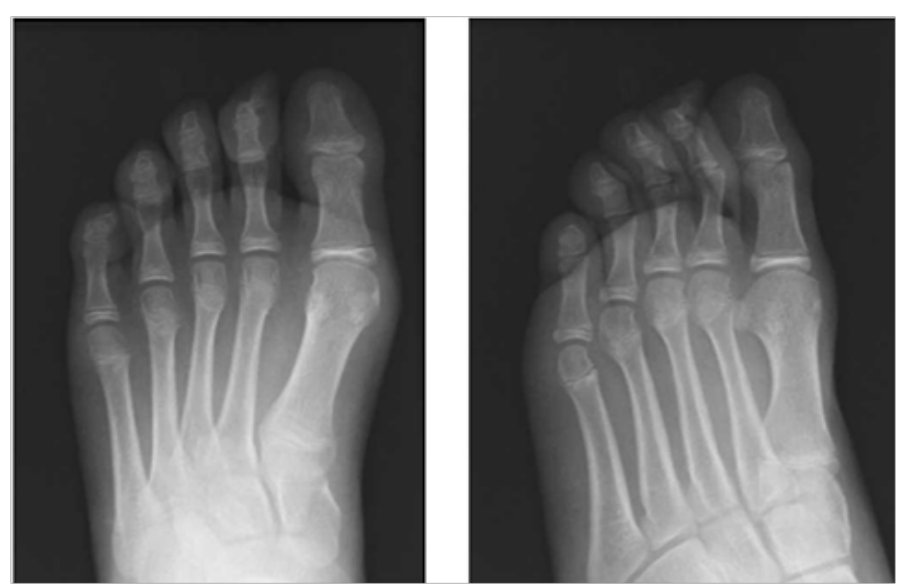

Figure 3 Radiography of the right foot showed a bony excrescence in the distal phalanx of the second toe of the right foot.

\section{Discussion}

Osteochondromas are benign osteocartilaginous outgrowths. Their mechanism of production in osteochondromas is still elusive. ${ }^{3}$ While some believe they arise from an abnormal periosteal development, ${ }^{9}$ others consider a congenital origin secondary to genetic activation, this proved to be true in the case of multiple osteochondromas associated with EXT1/2 gene mutations. ${ }^{2,3}$ They are more frequently observed in adolescents and young adults, and in those located in the distal phalanx of fingers and toes, age of presentation ranges from 10 to 25 years ${ }^{3,9-11}$ Grisafi et al. ${ }^{7}$ and Schulze and Hebert ${ }^{9}$ referred males are twice as affected as females, and history of trauma or microtraumasuch as an ill-fitted shoe is frequently found. ${ }^{3}$ Clinically, they present as firm solitary nodules, with or without associated nail plate deformity, and run asymptomatic or with pain and oppression in the affected finger or toe. ${ }^{9,11}$ Clinical differential diagnosis of either subungual osteochondromas or exostosis includes ingrown toenails, verruca vulgaris, pyogenic granulomas, glomus tumors, fibromas, keratoacanthomas, squamous cell carcinomas, subungual malignant melanomas as well as bacterial or mycotic infections. ${ }^{8,12}$

Subungual osteochondroma's US findings have been briefly described as well-defined rounded hypoechoic images with increased vascularization ${ }^{13,14}$ our case showed an hypoechoic band in keeping with the cartilaginous cap, bounded by an echogenic bony protuberance on its deep surface, enlarging the nail bed and displacing upwards the nail plates; however, Color Doppler US did not reveal vascularity. On the other hand, subungual exostosis are described as hyperechoic linear images, with posterior acoustic shadowing, located immediately under the nail plates and directly connected to the bone margin of the distal phalanx, with a relative hypovascularity or mild vascularity. ${ }^{14-17}$ The nail bed is similarly enlarged and displaced upward.

Radiography shows the presence of juxtaepiphyseal protuberances, in proximity with the metaphyseal area- differentiating from subungual exostosis- of long or short bones, in continuity with the underlying bone cortex and medullary channel. ${ }^{1,2,9}$

On histology, a hyaline cartilage cap with a high number of chondrocytes is observed, unlike subungual exostosis in which the cap is composed of fibrocartilage. ${ }^{2,8,9}$ Surgery is the treatment of choice in symptomatic cases and in those tumors with vascular or nerve compression. ${ }^{2}$

\section{Conclusion}

In the diagnostic assessment of nail lesions sonography has become a useful, noninvasive adjunctive tool, allowing a realtime evaluation, widening our initial differential diagnosis. Unlike exostosis, subungual osteochondromas have barely been described in revised literature, perhaps due to similarity between both entities. However, we believe in the importance of discriminating in what increasingly seems to be two separate entities, imaging included.

\section{Acknowledgments}

The authors wish to acknowledge the constant support of the members of the Dermatology department in the Hospital Complex of Toledo.

\section{Conflicts of interest}

The author declares that there is no conflicts of interest.

\section{References}

1. Murphey MD, Choi JJ, Kransdorf MJ, et al. Imaging of osteochondroma: variants and complications with radiologic-pathologic correlation. Radiogr Rev PublRadiol Soc N Am Inc. 2000;20(5):1407-1434. 
2. Vázquez-Flores H, Domínguez-Cherit J, Vega-Memije ME, et al. Subungual osteochondroma: clinical and radiologic features and treatment. Dermatol Surg Off Publ Am Soc Dermatol Surg Al. 2004;30(7):1031-1034.

3. Eliezri YD, Taylor SC. Subungualosteochondroma. Diagnosis and management. J Dermatol Surg Oncol. 1992;18(8):753-758.

4. Öztürk R, Arikan M, Özanlağan E, et al. Management of chondrosarcomas localized to phanaxes. 2020;11:171-174.

5. Dumontier CA, Abimelec P. Nail unit enchondromas and osteochondromas: a surgical approach. Dermatol Surg Off Publ Am Soc Dermatol Surg Al. 2001;27(3):274-279.

6. Ilyas W, Geskin L, Joseph AK, et al. Subungual exostosis of the third toe. J Am Acad Dermatol. 2001;45(6 Suppl):200-201.

7. Grisafi PJ, Lombardi CM, Sciarrino AL, et al. Three select subungual pathologies: subungual exostosis, subungual osteochondroma, and subungual hematoma. Clin Podiatr Med Surg. 1989;6(2):355-364.

8. Göktay F, Atıș G, Güneș P, et al. Subungual exostosis and subungual osteochondromas: a description of 25 cases. Int $J$ Dermatol. 2018;57(7):872-881.

9. Schulze KE, Hebert AA. Diagnostic features, differential diagnosis, and treatment of subungual osteochondroma. Pediatr Dermatol. 1994;11(1):39-41.
10. van Alphen JC, te Slaa RL, Eulderink F, et al. Solitary osteochondroma of the scaphoid: a case report. J Hand Surg. 1996;21(3):423-425.

11. Tchernev G, Grigorov Y, Philipov S, et al. Subungual Exostosis in a Young Soccer Player. Open Access Maced J Med Sci. 2018 25;6(1):5254.

12. Morais P. Subungual nodule of the great toe. Aust Fam Physician. 2013;42(4):213-215.

13. Aluja Jaramillo F, Quiasúa Mejía DC, Martínez Ordúz HM, et al. Nai unit ultrasound: a complete guide of the nail diseases. $J$ Ultrasound. 2017;20(3):181-192.

14. Vidal D, Echeverria B, García-Gavín J, et al. Ultrasound in the management of nail disease. Actas Dermosifiliogr. 2015;106 Suppl $1: 60-66$.

15. Wortsman X, Wortsman J, Soto R, et al. Benign tumors and pseudotumors of the nail: a novel application of sonography. J Ultrasound Med Off J Am Inst Ultrasound Med. 2010;29(5):803-816.

16. Chiou H-J, Chou Y-H, Chiu S-Y, et al. Differentiation of benign and malignant superficial soft-tissue masses using grayscale and color doppler ultrasonography. J Chin Med Assoc JCMA. 2009;72(6):307315.

17. DaCambra MP, Gupta SK, Ferri-de-Barros F. Subungual exostosis of the toes: a systematic review. Clin Orthop. 2014;472(4):1251-1259. 